\title{
Projection of Living Arrangements of the Elderly in Japan Using INAHSIM
}

\author{
Tetsuo, Fukawa ${ }^{1,2,3,{ }^{*}}$ \\ ${ }^{1}$ Institution for Future Welfare, Tokyo, Japan \\ ${ }^{2}$ Musashino University, Tokyo, Japan \\ ${ }^{3}$ Hitotsubashi University, Tokyo, Japan \\ *Correspondence: 1-26-16-302 Shoto, Shibuya-ku, Tokyo 150 Japan. Tel: 81-3-6407 9700. E-mail: fukawa@ifwj.org
}

Received: June 8, 2018 Accepted: June 26, $2018 \quad$ Online Published: July 20, 2018

doi:10.5430/sass.v5n2p34 URL: https://doi.org/10.5430/sass.v5n2p34

\begin{abstract}
By using a dynamic micro-simulation model named INAHSIM, we conducted a population-household projection in Japan for the period of 2015 to 2070 . Due to rapid aging of the population, the distribution of the elderly (65 years old or older) by living arrangements has a profound impact on the social system. Especially, the choice of the elderly among a) living in one-person households, b) co-residing with child households, and c) living in institutions, are crucial indicators for the future social burden of the elderly in Japan. In this paper, we projected the number and proportion of the elderly by living arrangement in future years. Trends of those elderly who have little relatives, therefore having high risk of dying in solitude, were also featured.
\end{abstract}

Keywords: dynamic micro-simulation, population-household projection, living arrangements of the elderly, co-residing with a child, institution rate, solitary rate

\section{Introduction}

Most elderly people value their independence and would prefer to continue to live in their own homes. Long-term care (LTC) policies in many OECD countries aim to help people to live independently in the community for as long as possible and rates of home care have increased in recent years (Muir, 2017). Most older adults prefer to age in place, that is, in their homes and communities, and this is unlikely to change in the foreseeable future (Johnson Jr. \& Appold, 2017). Our challenge therefore is to figure out how to ensure that as many older adults as possible can actualize their desire to live out their lives in their home and community (Cirillo, 2017). Elderly people who are burdened by excessive housing costs or who occupy rental properties will likely encounter the most difficulty aging in place (Johnson Jr. \& Appold, 2017).

Japan's population is aging rapidly as fertility rate remains low and life expectancy continues to extend. Living arrangements of the elderly have changed so far and further change may happen. Based on the 2015 Population Census, among the Japanese elderly population aged 65 or over, 17.7\% live in one-person households, 34.9\% in couple-only households, 36.3\% live with the child generation, and 6.0\% live in institutions (Fukawa, 2017a). Living arrangements of Japanese elderly are still quite unique as seen in Table 1. Co-residing with a child was once very common among Japanese elderly. The co-residing rate of the elderly aged 65 or over declined from 70\% in 1980, through $50 \%$ in 2000 , and to $36 \%$ in 2015 . This trend demonstrates that co-residing is moving away from behavior based upon traditional obligation ideology, becoming a behavior based upon strategic choices for maximizing mutual benefits and adapting to the changing societal environment (Hiroshima, 1987).

INAHSIM is a dynamic micro-simulation model, which was first developed in 1984-85 in Japan (Note 1). From the INAHSIM model, we can obtain a population-household projection in a coherent manner as well as dynamic statistics which are difficult to obtain from static surveys or macro simulation (Fukawa, 2012). As an example of such output, we prepared an index named solitary rate of the elderly.

In this paper, basic features of the INAHSIM 2018 Simulation were described in Section 2, and results about living 
arrangements of the elderly were shown in Section 3. We discussed how the living arrangements of the elderly affect future Japanese society in Section 4, focusing on institution rate and solitary rate (see below). Japan is already the most aged country among major developed countries, and its aging rate (the proportion of those who are 65 years old or over to the total population) is expected to increase around 38\% in 2065 (National Institute of Population and Social Security Research, 2017). Therefore, Japan must deal with issues related to aging societies as a front runner among developed countries.

Table 1. Living Arrangements of the Elderly (65+) in Six Countries: 2014

\begin{tabular}{lcccccc}
\hline & France & Germany & Japan a & Sweden & UK & USA \\
\hline One-person senior household & 37.0 & 36.5 & 17.7 & 36.8 & 32.1 & 27.1 \\
2 or more seniors in household & 51.0 & 49.3 & 34.9 & 54.8 & 47.7 & 41.2 \\
Other household types & 12.0 & 14.3 & 47.4 & 8.4 & 20.2 & 31.7 \\
\hline
\end{tabular}

a: 2015

Note: Japanese data is based on Fukawa (2017a).

Source: OECD Affordable Housing Database (version December 2016).

\section{INAHSIM 2018 Simulation}

\subsection{Basic Features}

In the INAHSIM 2017 Simulation--setting 2015 as the start year--a population-household projection was done for the period of 2015-2065 (Fukawa, 2017b). Observing the basic framework of the 2017 Simulation, the 2018 Simulation had kept the following characteristics: a) the Initial Population was formed by using the INAHSIM model itself; b) the dependency of the elderly was formed based on the data of the Long-term Care (LTC) Insurance; and c) institutions were included in the model as a possible option for the elderly to move (Fukawa, 2017b). However, the 2018 Simulation had the following features different from the 2017 Simulation:

- Base year was same (2015), but the simulation period was extended to 2070;

- Initial Population was created using the past 4 years of data (1990, 2000, 2010, and 2015);

- One-year dependency transition of the elderly was further improved;

- Standard merger rate of aged parent(s) with a child was modified; and

- Probability of the elderly to move to an institution was modified.

Various transition probabilities were used in the model. The death rate is given by age (single year of age) and sex for those who are less than 65 years old, but for those who are 65 years old or over it is determined by dependency transition which is given by age group and sex. Concerning household merger, we employed four kinds of rates (Note 2).

The dependency of the elderly aged 65 or over is classified into 4 levels as follows (Fukawa, 2012):

Level 0: No disability and completely independent;

Level 1: Some disability but basically independent;

Level 2: Slightly or moderately dependent;

Level 3: Heavily dependent; and

Level 4: Death.

Levels 2 and 3 correspond to persons eligible for the LTC Insurance, and Level 3 corresponds to care need assessments 4 and 5 in particular.

Co-resident rate will be influenced by the merger rate of aged parent(s) with a child, which changes according to marital status, average age and dependency of the elderly.

We denote $[\mathrm{x}, \mathrm{y}]$ if the number of same-generation relatives (namely brothers-sisters as well as their spouses) is $\mathrm{x}$ and the number of child-generation relatives (namely children including nephews and nieces as well as their spouses) is $y$, and we defined solitary rate of the elderly $(65+)$ as the percentage of those who are $[0 \& 0]$ or $[1 \& 0]$. 


\subsection{Simulation Cases}

The total fertility rate was assumed to remain the same throughout the simulation period, and we assumed three levels (TFR $=1.4,1.6$ and 1.8). On the other hand, the death rate was assumed to decline gradually, with resulting life expectancy at birth as 85.3 years for males and 91.2 years for females in 2070 . The other transition probabilities, including the possibility of the elderly to move to institutions, remain the same throughout the simulation period.

We assumed two cases concerning the possibility of the elderly to move into institutions. Standard Case traces the situations in 2015, and Independent Case represents a society where the elderly's use of institutions is less likely. This process occurred separately from the merger of aged parent(s) with a child.

\subsection{Total Population and Aging Rate in 2020-2070}

According to the 2018 simulation, the total population continues to decline from 127 million in 2015 to 79 million in 2070 , while aging of the population will continue from $27 \%$ in 2015 to $39 \%$ in 2070 , if future TFR remains at 1.4 (Fig. 1). Future total population will be more or less in line with the result of the latest official population projection published by the IPSS (National Institute of Population and Social Security Research) in April 2017 (IPSS, 2017), and future aging rate for the case of Standard \& TFR=1.4 will be similar to the Middle scenario by the IPSS, as shown in Figure 1.

(a) Total population

(b) Aging rate

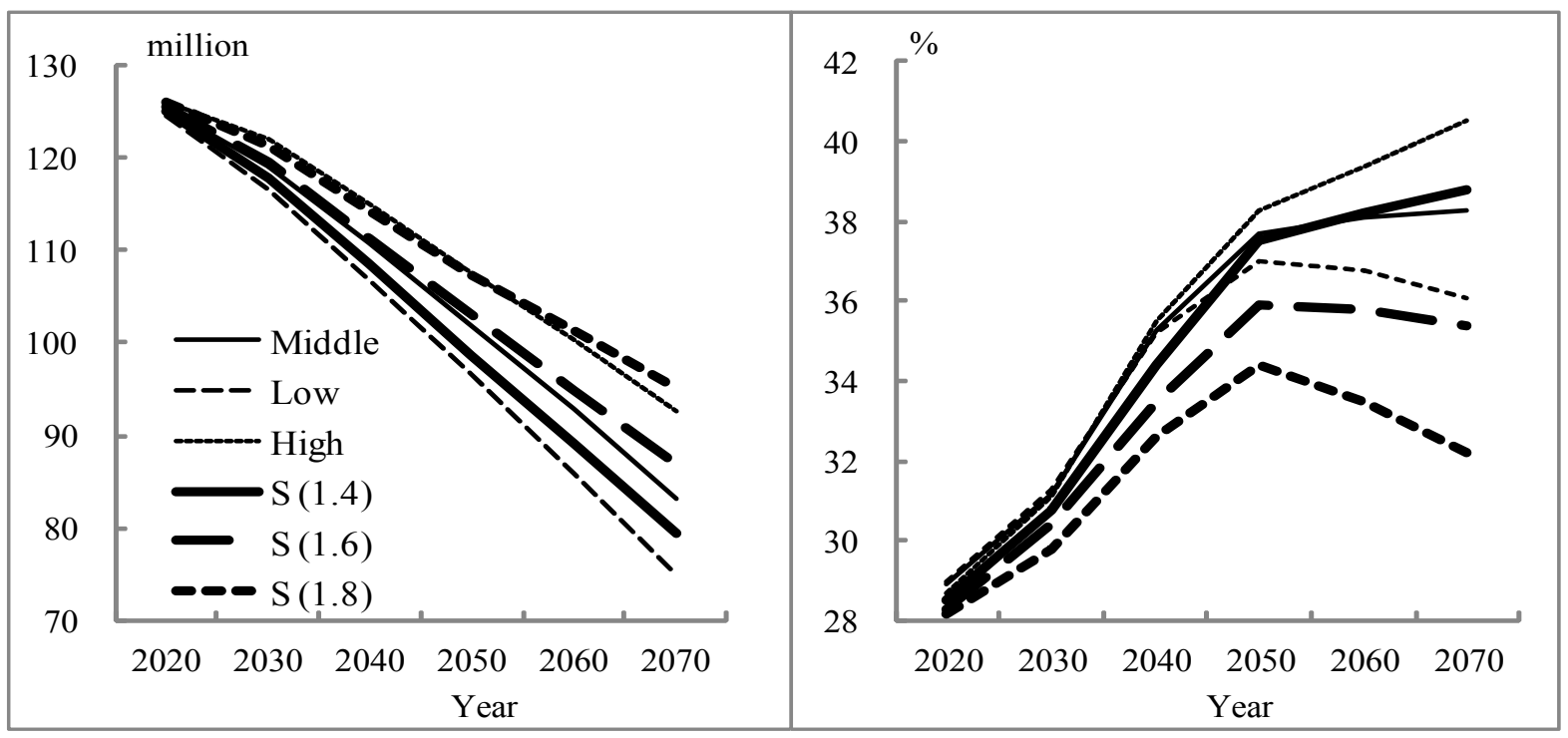

Note: Middle, Low, High mean middle, low, and high scenarios of the Population Projection by the IPSS as of April 2017 respectively.

Figure 1. Total Population and Aging Rate

\section{Simulation Results}

\subsection{Living Arrangements of the Elderly}

Table 2 shows the living arrangements of the elderly (65+) from 2020 to 2070 (the others which shared 5-6\% were eliminated from the table). According to the simulation, the proportion of one-person households will increase from the present 18\% to 30\% in Standard Case and 34\% in Independent Case in 2060, and it will decrease afterwards. The proportions of couple-only households as well as co-residents with a child will continue decreasing throughout the projection periods. However, the proportion of those elderly who live in institutions (institution rate), which was $6 \%$ in 2015, will steadily increase throughout the projection periods to $15 \%$ in Standard Case and $8 \%$ in Independent Case in 2070. 
Table 2. Living Arrangements of the Elderly: 2020-2070

\begin{tabular}{|c|c|c|c|c|c|c|c|c|c|c|c|c|c|c|c|c|}
\hline \multirow{3}{*}{ Year } & \multicolumn{8}{|l|}{$65+$} & \multicolumn{8}{|l|}{$85+$} \\
\hline & \multicolumn{3}{|c|}{ Standard Case } & \multirow[b]{2}{*}{$\mathrm{I}$} & \multicolumn{4}{|c|}{ Independent Case } & \multicolumn{3}{|c|}{ Standard Case } & & \multicolumn{4}{|c|}{ Independent Case } \\
\hline & $1 \mathrm{P}$ & $\mathrm{Cy}$ & Co & & $1 \mathrm{P}$ & $\mathrm{Cy}$ & $\mathrm{Co}$ & $\mathrm{I}$ & $1 \mathrm{P}$ & $\mathrm{Cy}$ & Co & & $1 \mathrm{P}$ & $\mathrm{Cy}$ & Co & $\mathrm{I}$ \\
\hline 2020 & 21.4 & 34.4 & 32.3 & 6.6 & 21.9 & 35.8 & 32.6 & 4.1 & 19.7 & 11.0 & 44.8 & 19.9 & 22.1 & 14.1 & 46.2 & 13.1 \\
\hline 2030 & 24.3 & 29.6 & 32.5 & 8.2 & 25.6 & 31.4 & 33.2 & 3.9 & 20.8 & 11.2 & 42.2 & 22.4 & 25.3 & 13.0 & 46.1 & 11.2 \\
\hline 2040 & 27.7 & 26.5 & 30.6 & 9.0 & 29.5 & 28.0 & 31.7 & 4.1 & 22.5 & 10.7 & 39.7 & 23.6 & 27.8 & 13.7 & 43.5 & 11.8 \\
\hline 2050 & 29.9 & 25.1 & 28.9 & 10.3 & 32.1 & 26.5 & 30.1 & 4.8 & 24.7 & 9.9 & 35.5 & 26.6 & 30.3 & 12.8 & 39.2 & 14.2 \\
\hline 2060 & 30.1 & 22.3 & 28.3 & 13.3 & 34.1 & 23.7 & 29.6 & 6.4 & 25.3 & 9.5 & 31.8 & 30.5 & 34.4 & 12.9 & 33.6 & 15.6 \\
\hline 2070 & 29.6 & 21.5 & 27.6 & 15.0 & 33.6 & 23.8 & 27.9 & 7.9 & 24.7 & 7.6 & 30.6 & 33.9 & 33.8 & 10.6 & 32.9 & 19.2 \\
\hline
\end{tabular}

(Note) 1P: One-person, Cy: Couple only, Co: Co-resident with a child, I: Institution

The living arrangements of the elderly are rather different between males and females. Reflecting the difference in death rates, the number and proportion of one-person households is much higher for females than males in 2015. However, the increase in the proportion of one-person households among elderly males is faster than females, and both the number and proportion of one-person households for males are catching up to that for females in 2070 (Fig. 2).

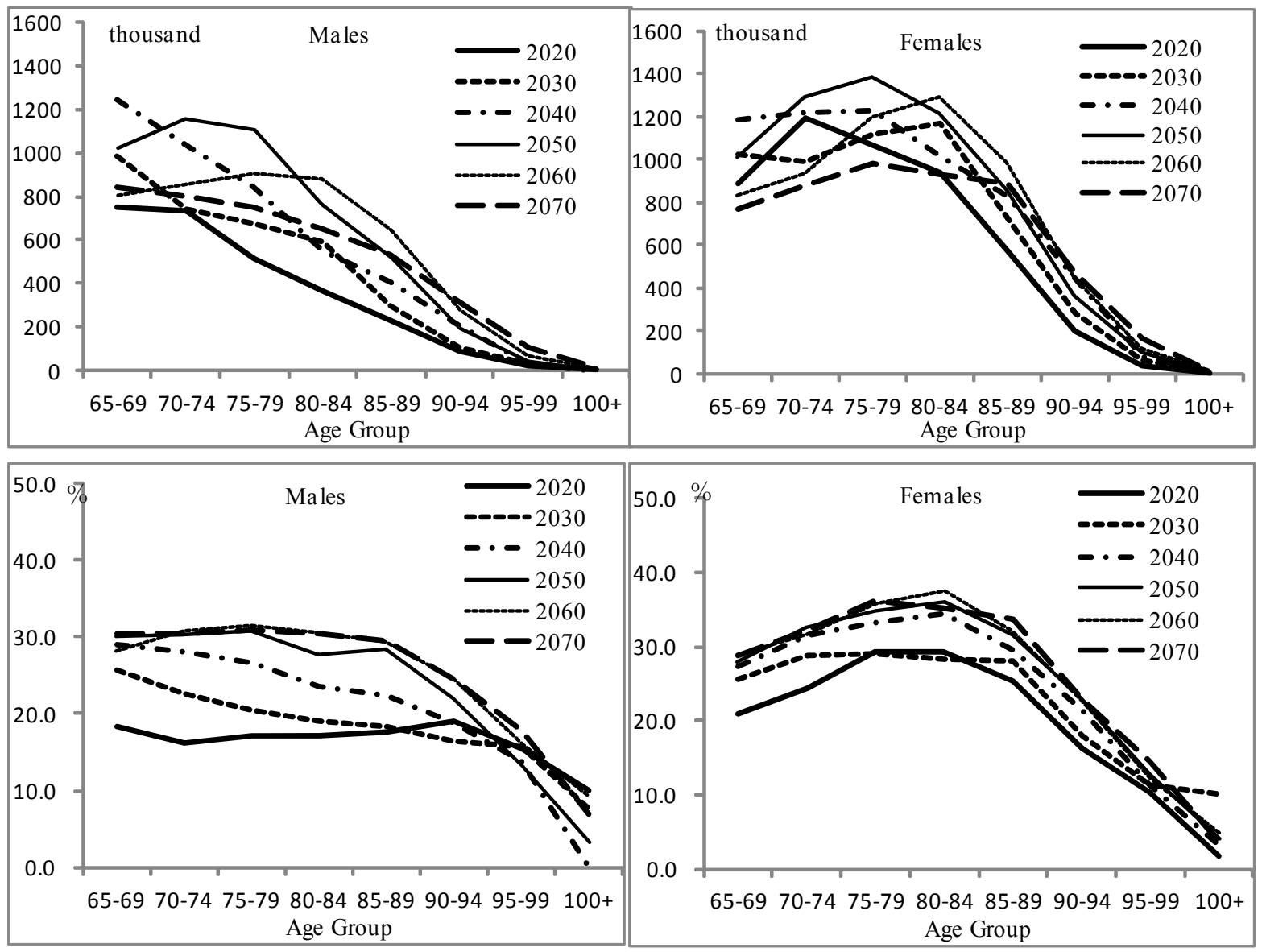

Figure 2. Number and Proportion of the Elderly Living in One-Person Households According to Age Group and Sex: 2020-2070 
Figure 3 shows the proportion of the elderly living in couple-only households according to age group and sex. The rate is higher for males than females at each age group, and the rate will further gradually decline for both males and females in future years.

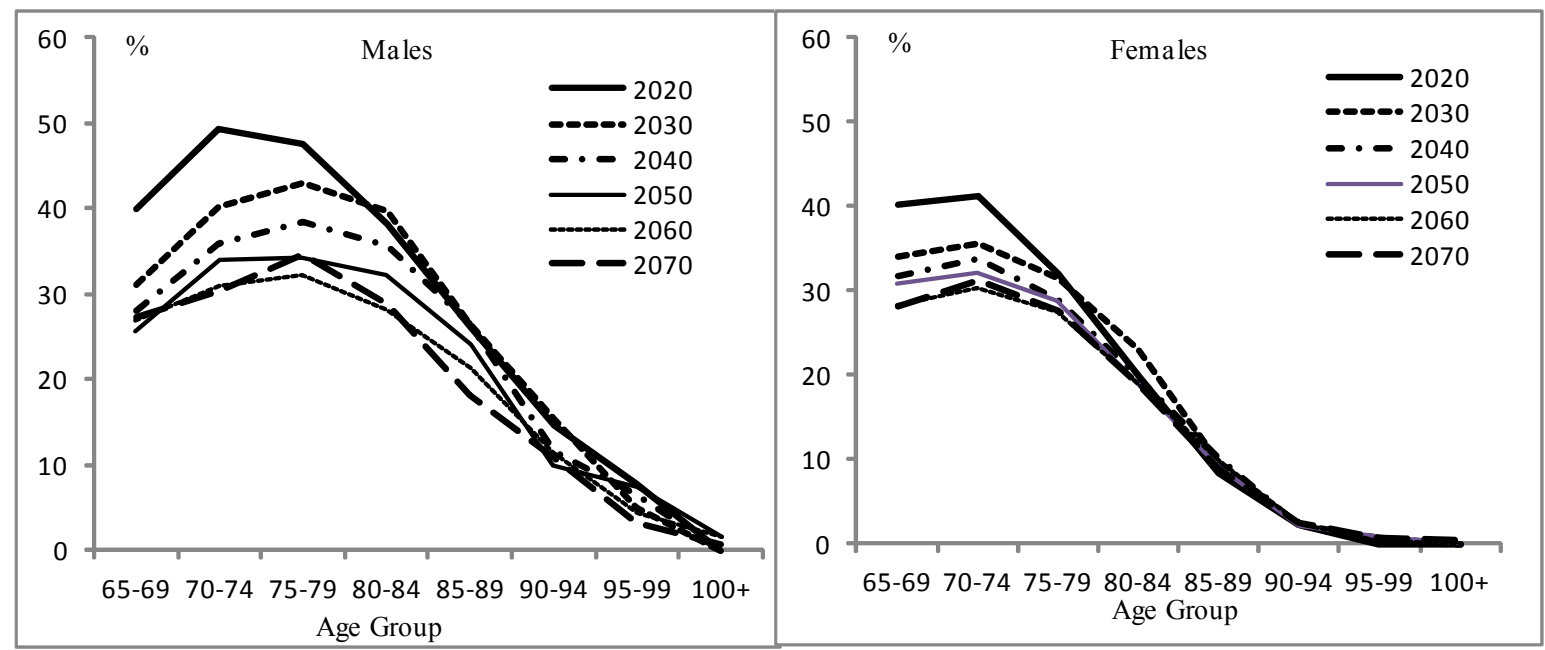

Figure 3. Proportion of the Elderly Living in Couple Only Households According to Age Group and Sex: 2020-2070

Figure 4 shows the co-resident rate of the elderly according to age group and sex from 2020 to 2070 . The co-resident rate of the elderly increases with age, and the historical trend of declining co-resident rates will be maintained in future years.

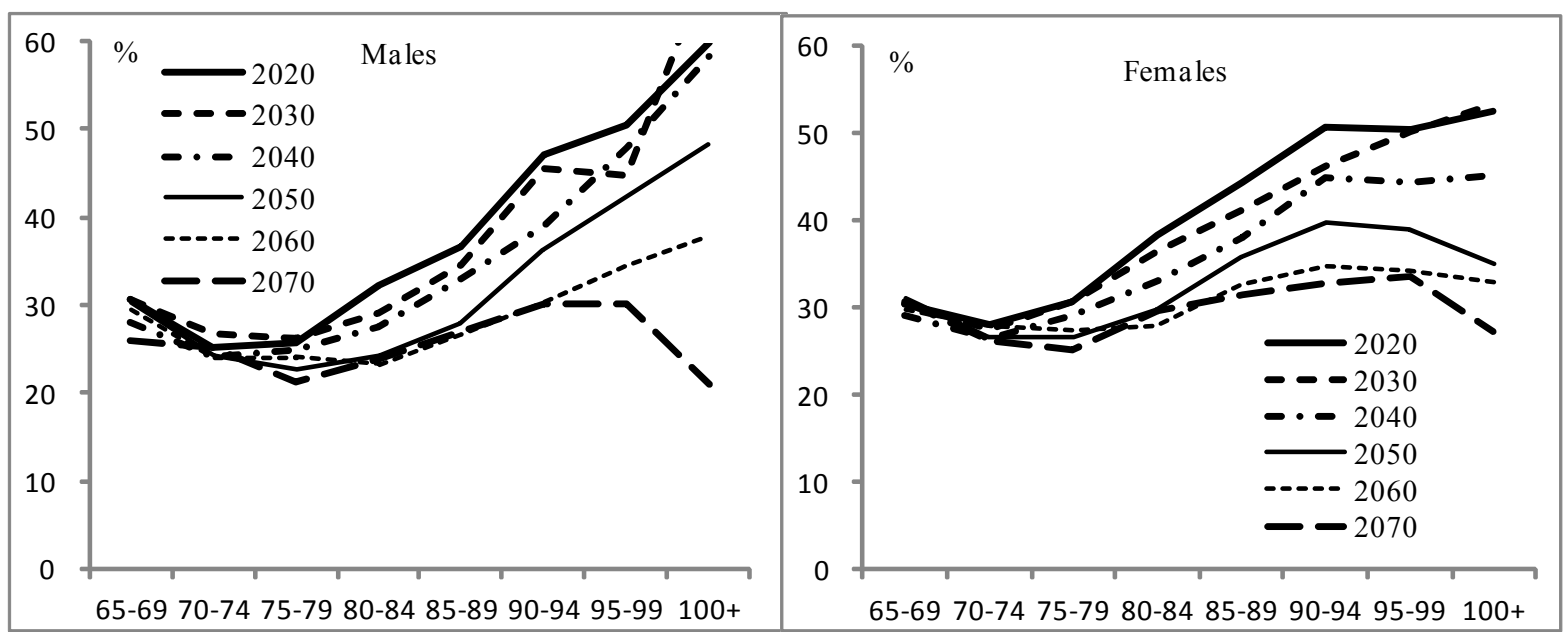

Figure 4. Proportion of the Elderly Living with Child Generation According to Age Group and Sex: 2020-2070

The co-resident rate of the elderly aged 65 or over declined from $70 \%$ in 1980 to $50 \%$ in 2000 , and it was $36 \%$ in 2015. Future co-resident rate of the elderly aged 65 or over will remain at around $30 \%$ if present trends continue to exist in future (Fig. 5). 


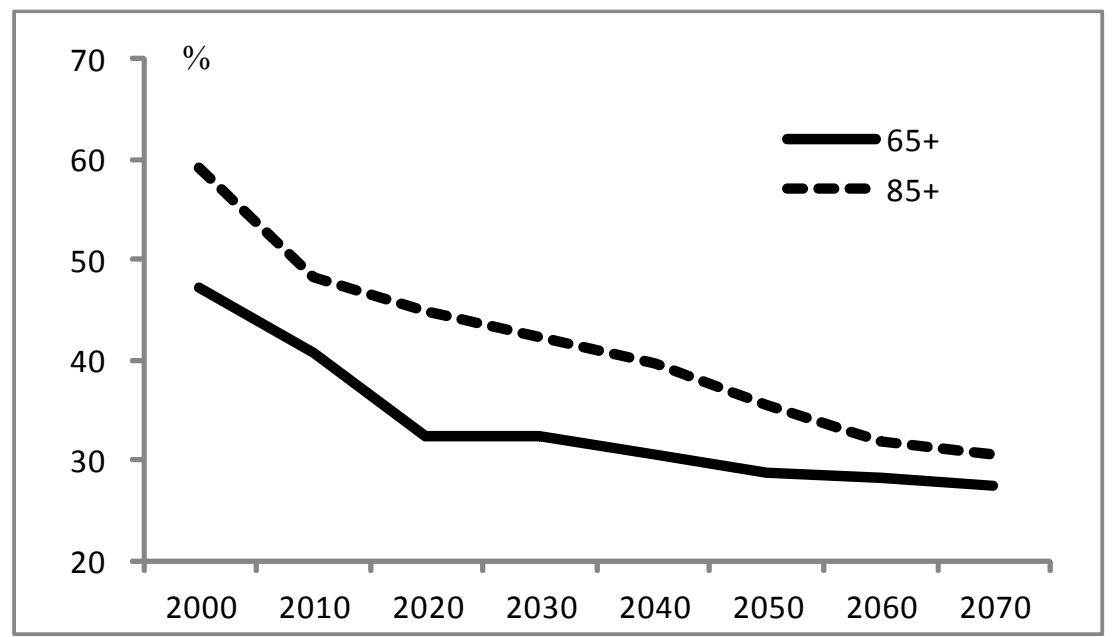

Figure 5. Co-Resident Rate of the Elderly $(65+\& 85+)$ with Child: 2000-2070

The proportion of female elderly staying in institutions was 7.6\% in 2015, which was twofold of male elderly (Table 3). The institution rate of the elderly will increases steadily from $6.6 \%$ in 2020 to $15 \%$ in 2070 . Female elderly have a higher value of institution rate and lower value rate of having a spouse than male elderly throughout simulation period.

Table 3. Living Arrangements of the Elderly (65+) by Sex: 2020-2070, Standard Case

\begin{tabular}{|c|c|c|c|c|c|c|c|c|c|c|c|c|c|c|c|c|c|c|c|c|c|}
\hline \multirow[t]{2}{*}{ Year } & \multicolumn{2}{|c|}{ Total } & \multicolumn{12}{|c|}{ Males } & \multicolumn{2}{|c|}{ Females } & \\
\hline & $1 \mathrm{P}$ & $\mathrm{Cp}$ & \multicolumn{4}{|c|}{ Co-resident with child } & $\mathrm{I}$ & $1 \mathrm{P}$ & $\mathrm{Cp}$ & \multicolumn{4}{|c|}{ Co-resident with child } & $\mathrm{I}$ & $1 \mathrm{P}$ & $\mathrm{Cp}$ & \multicolumn{4}{|c|}{ Co-resident with child } & $\mathrm{I}$ \\
\hline 2015 & 17.7 & 34.9 & 5.6 & 7.8 & 15.5 & 7.2 & 6.0 & 13.3 & 43.2 & 6.9 & 4.6 & 20.3 & 2.8 & 3.8 & 21.1 & 28.5 & 4.7 & 10.3 & 11.9 & 10.5 & 7.6 \\
\hline 2020 & 21.4 & 34.4 & 5.3 & 8.3 & 12.4 & 6.2 & 6.6 & 17.3 & 41.6 & 6.3 & 4.2 & 15.5 & 3.5 & 5.3 & 24.6 & 28.8 & 4.6 & 11.5 & 10.1 & 8.2 & 7.7 \\
\hline 2030 & 24.3 & 29.6 & 4.7 & 8.3 & 12.5 & 7.0 & 8.2 & 21.4 & 35.6 & 5.5 & 4.7 & 15.8 & 3.8 & 6.8 & 26.6 & 24.8 & 4.1 & 11.0 & 9.9 & 9.4 & 9.3 \\
\hline 2040 & 27.7 & 26.5 & 4.0 & 7.3 & 12.4 & 6.9 & 9.0 & 25.9 & 31.2 & 4.7 & 4.3 & 15.1 & 3.9 & 7.5 & 29.1 & 22.6 & 3.5 & 9.7 & 10.2 & 9.2 & 10.3 \\
\hline 2050 & 29.9 & 25.1 & 3.9 & 6.6 & 12.2 & 6.2 & 10.3 & 28.8 & 29.0 & 4.4 & 4.1 & 14.6 & 3.6 & 9.1 & 30.7 & 22.0 & 3.5 & 8.7 & 10.3 & 8.3 & 11.4 \\
\hline 2060 & 30.1 & 22.3 & 3.8 & 6.8 & 11.6 & 6.1 & 13.3 & 29.2 & 26.2 & 4.4 & 4.3 & 13.8 & 3.7 & 11.6 & 30.8 & 19.2 & 3.4 & 8.8 & 9.8 & 8.0 & 14.7 \\
\hline 2070 & 29.6 & 21.5 & 4.0 & 6.3 & 11.4 & 5.9 & 15.0 & 29.1 & 25.3 & 4.4 & 3.8 & 13.5 & 3.6 & 12.9 & 29.9 & 18.4 & 3.6 & 8.3 & 9.8 & 7.8 & 16.7 \\
\hline
\end{tabular}

(Note 1) 1P: One-person、Cp: Couple only

a, b: Co-resident with child (Couple) of elderly couple (a) or elderly without spouse (b).

c, d: Co-resident with child (Without spouse) of elderly couple (c) or elderly without spouse (d).

I: Institution

(Note 2) Values in 2015 above the dotted line are based on Fukawa (2017a).

Figure 6 shows the proportion of the elderly living in institutions according to age group and sex from 2020 to 2070 . The proportion of the elderly living in institutions increases with age for both males and females, and due to aging of the elderly population, the proportion will steadily increase among the oldest elderly for both males and females. 


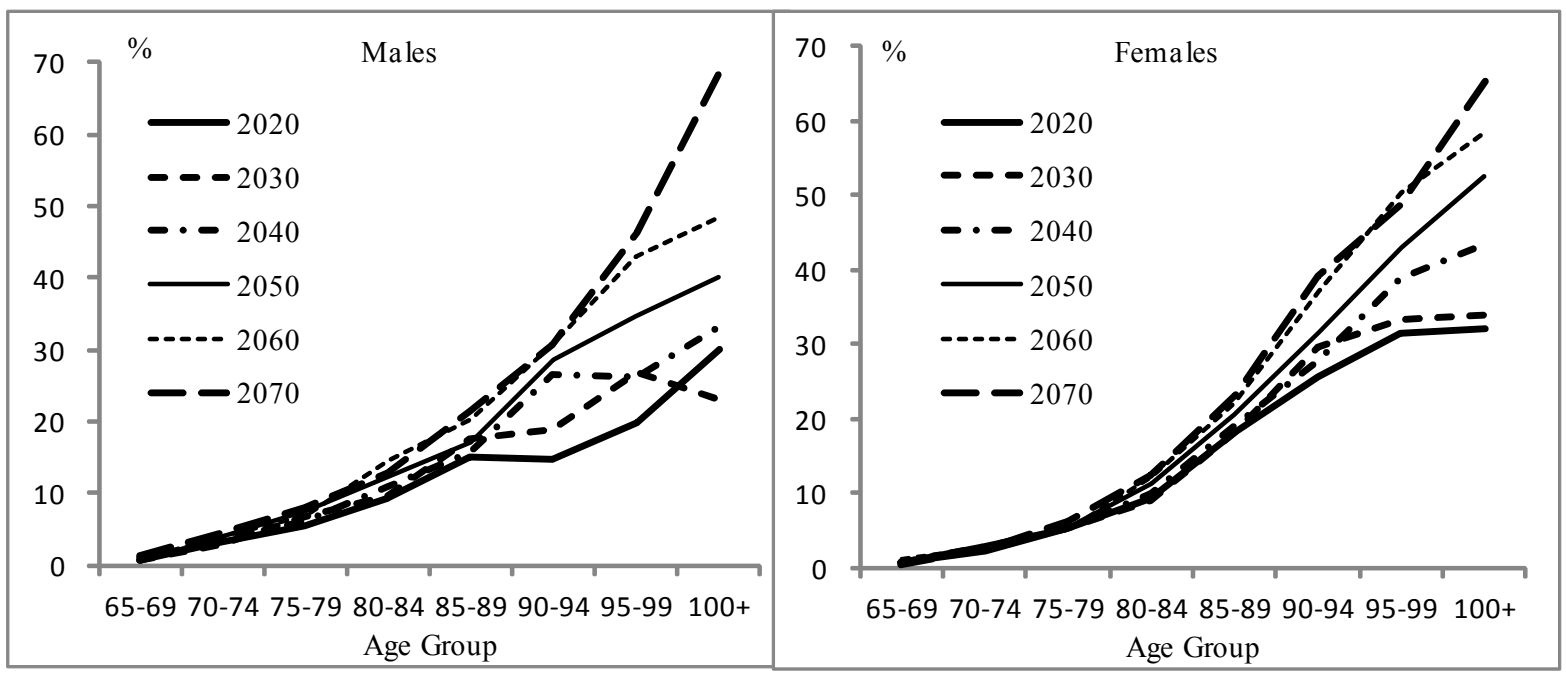

Figure 6. Proportion of the Elderly Living in Institutions According to Age Group and Sex: 2020-2070

\subsection{Elderly in Solitude (Solitary Rate)}

Table 4 shows the number and proportion of those elderly (65+) who have little relatives, namely no brothers-sisters/their spouses and no children/their spouses $(=[0 \& 0])$, or 1 brothers-sisters/their spouses and no children/their spouses $(=[1 \& 0])$. The proportion of those elderly aged 65 or over who have little relatives (solitary rate) increases from $1.6 \%$ in 2020 to $10 \%$ in 2070 . Similarly, the proportion of those elderly aged 85 or over who have little relatives increases from $3 \%$ in 2020 to $13 \%$ in 2070 . Assumptions on future fertility rate have little impact on the solitary rate.

Table 4. Number and Proportion of Those Elderly Who Have Little Relatives: 2020-2070 (a) $\mathrm{TFR}=1.4$

\begin{tabular}{|c|c|c|c|c|c|c|c|c|}
\hline & \multicolumn{3}{|c|}{$65+$} & \multicolumn{5}{|c|}{$85+$} \\
\hline \multirow[t]{2}{*}{ Year } & \multicolumn{3}{|c|}{ Number $(1,000)$} & \multirow[t]{2}{*}{$\%$} & \multicolumn{3}{|c|}{ Number $(1,000)$} & \multirow[t]{2}{*}{$\%$} \\
\hline & {$[0 \& 0]$} & {$\left[\begin{array}{lll}1 & \& & 0\end{array}\right]$} & Total & & {$[0 \& 0]$} & {$\left[\begin{array}{lll}1 & \& & 0\end{array}\right]$} & Total & \\
\hline 2020 & 435 & 132 & 567 & 1.6 & 147 & 30 & 177 & 3.0 \\
\hline 2030 & 696 & 288 & 984 & 2.7 & 161 & 43 & 204 & 2.8 \\
\hline 2040 & 1,179 & 590 & 1,769 & 4.7 & 179 & 89 & 268 & 3.0 \\
\hline 2050 & 1,808 & 810 & 2,618 & 7.1 & 422 & 167 & 589 & 6.9 \\
\hline 2060 & 2,127 & 920 & 3,047 & 8.9 & 800 & 262 & 1,062 & 10.5 \\
\hline 2070 & 2,211 & 914 & 3,125 & 10.1 & 1,015 & 281 & 1,296 & 12.8 \\
\hline
\end{tabular}

(b) $\mathrm{TFR}=1.8$

\begin{tabular}{|c|c|c|c|c|c|c|c|c|}
\hline & \multicolumn{3}{|c|}{$65+$} & \multicolumn{5}{|c|}{$85+$} \\
\hline \multirow[t]{2}{*}{ Year } & \multicolumn{3}{|c|}{ Number $(1,000)$} & \multirow[t]{2}{*}{$\%$} & \multicolumn{3}{|c|}{ Number $(1,000)$} & \multirow[t]{2}{*}{$\%$} \\
\hline & {$\left[\begin{array}{lll}0 & \& & 0\end{array}\right]$} & {$\left[\begin{array}{lll}1 & \& & 0\end{array}\right]$} & Total & & {$\left[\begin{array}{lll}0 & \& & 0\end{array}\right]$} & {$\left[\begin{array}{lll}1 & \& & 0\end{array}\right]$} & Total & \\
\hline 2020 & 417 & 136 & 553 & 1.6 & 113 & 35 & 148 & 2.6 \\
\hline 2030 & 739 & 257 & 996 & 2.8 & 198 & 25 & 223 & 3.1 \\
\hline 2040 & 1247 & 564 & 1,811 & 4.8 & 216 & 75 & 291 & 3.2 \\
\hline 2050 & 1778 & 782 & 2,560 & 6.9 & 465 & 150 & 615 & 7.3 \\
\hline 2060 & 1988 & 846 & 2,834 & 8.4 & 788 & 282 & 1,070 & 10.7 \\
\hline 2070 & 1920 & 738 & 2,658 & 8.7 & 963 & 296 & 1,259 & 12.4 \\
\hline
\end{tabular}


Figure 7 shows the solitary rate according to age group and sex from 2020 to 2070 . The rate will steadily increase in future years, and around $10 \%$ of the elderly in 2070 will face the risk of dying in solitude.

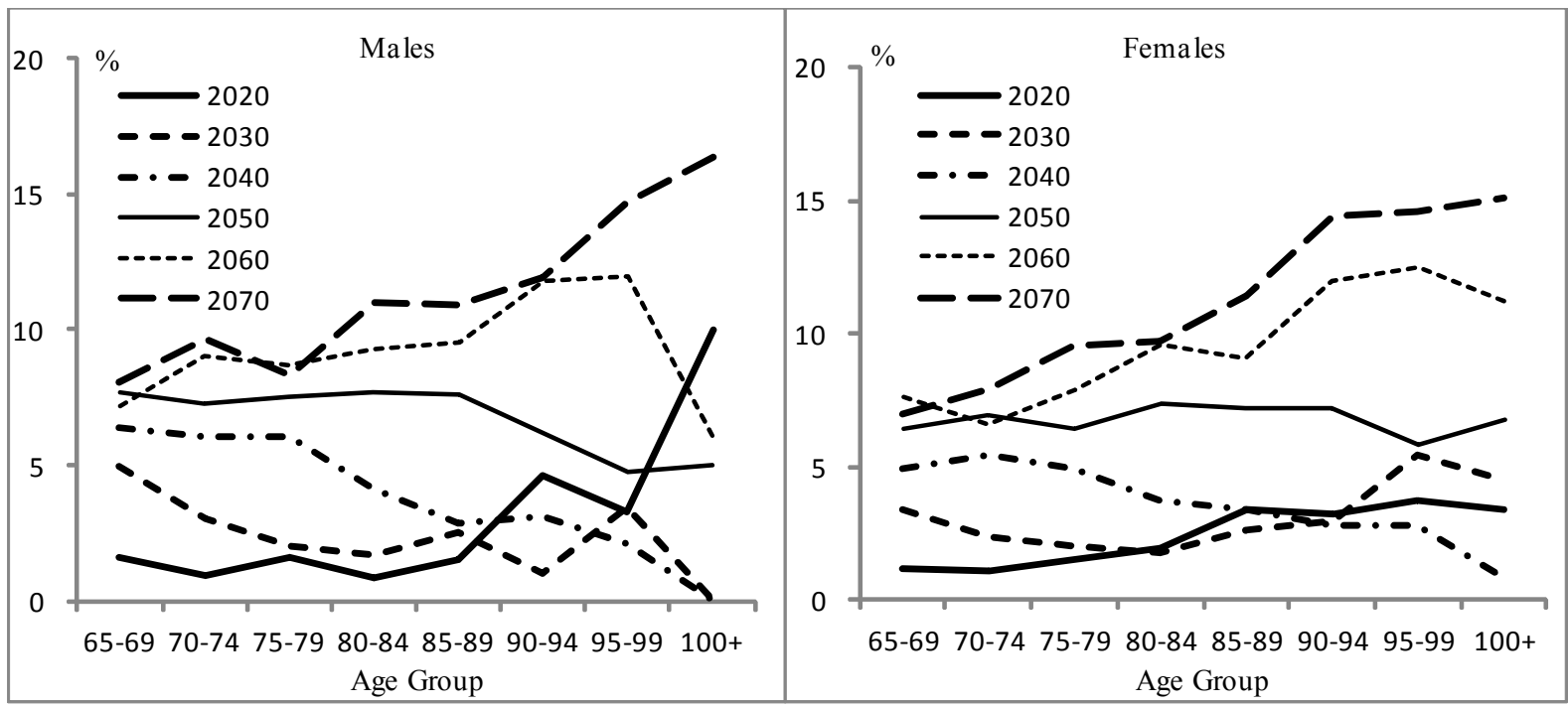

Figure 7. Proportion of Those Elderly Who Have Little Relatives According to Age Group and Sex 2020-2070

\section{Discussions}

Living arrangements are especially important for the elderly because they spend most of the day inside their homes. It is desirable if older persons are able to live where they wish, which is usually their own home. However, most people will, at some time, need to consider alternate living arrangements. Concerning living arrangements of the Japanese elderly in future years, we focused on those elderly who are living in one-person households, with children, and in institutions. Trends of those elderly who have little relatives, therefore having high risk of death in solitude, were also featured.

The followings are among the main findings from the simulation:

-The proportion of one-person households among the elderly will increase from $18 \%$ in 2015 to $30 \%$ in 2060 . The number and proportion of one-person households was much higher for females than males in 2015, but they will be parallel between males and females in 2070 .

-The share of couple-only households will decline throughout the simulation period.

-The co-resident rate of the elderly aged 65 or over will decline from $36 \%$ in 2015 to $28 \%$ in 2070 . It increases with age, and the historical trend of declining co-resident rates will continue but reach plateau around 2060.

-The proportion of those elderly who live in institutions will steadily increase from $6 \%$ in 2015 to $15 \%$ in 2070 . The number of female elderly staying in institutions is higher than that of male elderly. The proportion of the elderly living in institutions increases with age for both males and females, and it increases steadily from 2015 to 2070 with considerable similarity between males and females.

-The proportion of those elderly (65+) who have little relatives will increase from $1.6 \%$ in 2020 to $10 \%$ in 2070 . The solitary rate will steadily increase in future years, and it will reach $10 \%$ or above in 2070 for the elderly aged 80 or over.

The longer life expectancy of women has consequences in relation to the gender gap for elderly people living alone. According to the population and housing census, there were almost two million elderly women living alone in the EU-28 in 2011, which equated to more than one-third (36.9\%) of all women aged 65 and over, compared to just over one-sixth (16.9\%) of all men aged 65 and over were living alone (Eurostat, 2017). Among those aged 85 and over, the share of the population living alone was considerably higher, reaching $49.5 \%$ for women and $27.8 \%$ for men (Eurostat, 2017). In the US, after rising steadily for nearly a century, the share of older Americans who live alone has fallen since 1990, largely because women ages 65 to 84 are increasingly likely to live with their spouse or their children (Stepler, 2016). From 1990 to 2014, the share of older adults (65+) living alone declined by 3 percentage 
points, to $26 \%$ (males from $15 \%$ to $18 \%$, females from $38 \%$ to $32 \%$ ), but the share of the oldest old elderly ( $85+$ ) living alone increased from $37 \%$ to $40 \%$ (Stepler, 2016). Concerning Japanese elderly, the share of the population living alone will increase from $18 \%$ in 2015 to $30 \sim 34 \%$ in 2060, which is still lower than the present level in France, Germany and Sweden. Moreover, the gender gap for elderly people living alone may be narrowed in Japan according to our simulation.

Elderly with higher incomes tend to live alone as a way to preserve their privacy and independence, and many elderly people with higher incomes reside with their families because of the economic needs of their sons, who make use of their housing and financial resources (Fernandes Bolina \& Mara dos Santos Tavares, 2016). Despite problems such as feelings of loneliness, social isolation, physical limitations, and unbalanced meals, almost $90 \%$ of elderly people living alone in the US express a keen desire to maintain their independence (Kaplan \& Berkman, 2016). Concerning Japanese elderly, co-residing with a child was once very common and the co-residing rate of the elderly aged 65 or over was $70 \%$ in 1980 . But the rate has declined steadily through $50 \%$ in 2000 to $36 \%$ in 2015 , and it will further decline to $28 \%$ in 2070 . The rate of co-residence between adult children and elderly parents has continued to decrease due to fading value of filial piety (Ichimura et al., 2017), and this tendency will continue, but co-residing with children will remain in Japan as an option for the elderly in future years.

In 2011, the proportion of elderly people in the EU who were aged 65-84 years and living in an institutional household (health care institutions or institutions for retired or elderly persons) was $1.7 \%$, but the share was $12.6 \%$ among those aged 85 and over (7.6\% for males, 14.8\% for females) (Eurostat, 2017). According to our simulation, the proportion of elderly aged 85 and over who live in institutions will increase from $21 \%$ in 2015 to $34 \%$ in 2070, if we assume the prevalence of present institution rate. However, the institution rate in this paper is rather theoretical, considering only demand side, and the logic employed is natural but not reflecting actual scenes. In reality, institution rate depends on the availability of places on long term care institutions and their costs as well as on living arrangements, marital status, and dependency level of the elderly. In fact, it is difficult to maintain a one-person household if dependency level becomes high. Moreover, home care is often a more expensive way of managing severe needs than institutional care, but some older people prefer to remain in the community even with relatively severe needs, reading to a trade-off between controlling public expenditure and offering choice and independence to LTC users (Muir, 2017).

Connectivity--the ability to use technology, access services, travel easily and socialize-is a key issue as the population ages, and connectivity is crucial in allowing people to care for others, interact socially, participate in society, and access services such as health prevention and health treatment (Government Office for Science, 2016). In 2016, close to half ( $45 \%$ ) of those aged 65 to 74 years in the EU-28 used the internet at least once a week, and just over one quarter (26\%) of them made use of internet banking (Eurostat, 2017). Once the elderly are confident enough to use technology, they start using the internet actively, just like younger generations, and the internet opens up a wealth of new opportunities and services that may be of particular interest to the elderly (Eurostat, 2017).

Certain factors, such as education, labor force participation, contact with children, social interaction, and health, emerge as very important in the determinants of the likelihood of elderly depression in China, Korea, and Japan; there also are differences in the magnitude of these effects, and the importance of factors such as age, marriage, and wealth (Ichimura et al., 2017). In accordance with aging of the population, the cases of elderly death in solitude have been spotlighted in Japan recently. As community networks are diminishing, those elderly who have little relatives have high risk of death in solitude. According to our simulation, one out of ten elderly aged 65 or over will face the risk of death in solitude in 2070.

From the INAHSIM model, we can obtain a population-household projection in a coherent manner. Fukawa (2017c), for example, applied the simulation results to make a projection of health and long-term care expenditures in Japan. Due to rapid aging of the population in Japan, the distribution of the elderly by living arrangements and dependency level is important information for the future social system. The choice of the elderly among a) living in one-person households, b) co-residing with child households, and c) moving to institutions, has a profound impact on the society, especially on future LTC expenditures in Japan. The above mentioned results may change according to assumptions, but simulation results are useful in considering ways how to reorganize the social support systems under the circumstances of aging of the population and low fertility in Japan. In considering a suitable scale of social benefits, simulation results are indispensable to persuade the general public to accept a higher contribution or lower benefit. 


\section{Conclusions}

By using a dynamic micro-simulation model named INAHSIM, we conducted a population-household projection in Japan for the period of 2015-2070. Among the elderly (65 years old or older), the proportions of those who live in one-person households will increase from the present $18 \%$ to $30 \%$, living in institutions from $6 \%$ to $15 \%$, having little relatives from $1.6 \%$ to $10 \%$ in 50 years. All these trends suggest that there is quite a strong pressure for elderly care in Japan, and a paradigm change is necessary to construct a sustainable elderly care system. Simulation results are useful in considering ways how to reorganize the social support systems under the circumstances of aging of the population and low fertility in Japan.

\section{References}

Cirillo, Anthony. (2017). 10 Steps that Make Aging in Place a Reality," VeryWell.com. Retrieved February 28, from https://www.verywell.com/steps-aging-in-place-a-reality-197819

Eurostat. (2017). People in the EU- statistics on an ageing society.

Fernandes Bolina, A., \& Mara dos Santos Tavares, D. (2016). Living arrangements of the elderly and the sociodemographic and health determinants: a longitudinal study. Rev Lat Am Enfermagen, 24, e2737. https://dx.doi.org/10.1590/1518-8345.0668.2737

Fukawa, Tetsuo. (2012). Projection of Social Burden of the Elderly in Japan Using INAHSIM-II. Epidemiology Research International, Vol. 2012. Article ID 832325, 9 pages. https://doi.org/10.1155/2012/832325

Fukawa, Tetsuo. (2017a). Living arrangements of the elderly (65+) in 2015 based on the Population Census 2015. IFW DP series 2017-1. (in Japanese)

Fukawa, Tetsuo. (2017b). Population-household Projection in Japan: INAHSIM 2017 Simulation. IFW Discussion Paper Series 2017-E1.

Fukawa, Tetsuo. (2017c). Elderly Population Projection and Their Health Expenditure Prospects in Japan. Modern Economy, 8, 1258-1271. https://doi.org/10.4236/me.2017.811085

Government Office for Science (2016). Future of an Ageing Population.

Hiroshima, K. (1987). The Living Arrangements and Familial Contacts of the Elderly in Japan. International Institute for Applied Systems Analysis Working Paper 87-087.

Ichimura, Hidehiko, et al. (2017). Wellbeing of the Elderly in East Asia: China, Korea, and Japan. RIETI Discussion Paper Series 17-E-029.

Johnson Jr., James H., \& Appold, Stephen J. (2017). U.S. Older Adults: Demographics, Living Arrangements, and Barriers to Aging in Place. KENAN Institute.

Kaplan, Daniel B., \& Berkman, Barbara J. (2016). The Elderly Living Alone. Merck Manuals Professional Edition.

Muir, T. (2017). Measuring social protection for long-term care. OECD Health Working Papers, No. 93. https://doi.org/10.1787/a411500a-en

National Institute of Population and Social Security Research. (2017). Population Projections for Japan: 2015-2065. (in Japanese)

Stepler Renee (2016). Smaller Share of Women Ages 65 and Over Are Living Alone, Pew Research Center.

\section{Notes}

Note 1. INAHSIM is a dynamic micro simulation model, which simulates the actual society through changing personal segments, marital segments and household segments. The operation of each event is carried out once a year, and the order of operation is as follows: marriage, birth, death, divorce, separation of household, merger of household, and institutionalization.

Note 2. The following four rates are used for household mergers in the INAHSIM:

(a) Co-residency rate of adult child with parents upon marriage;

(b) Reuniting rate of adult child to the parent's household upon becoming widowed;

(c) Reuniting rate of adult child to the parent's household upon divorce; and

(d) Merger rate of aged parent(s) with child. 